\title{
Magic and Modulo Magicness of Paley Digraph
}

\author{
Parameswari.R, Rajeswari.R
}

\begin{abstract}
A special digraph arises in round robin tournaments. More exactly, a tournament $T_{q}$ with q players $1,2, \ldots$ , $q$ in which there are no draws. This gives rise to a digraph in which either $(u, v)$ or $(v, u)$ is an arc for each pair $u, v$. Graham and Spencer defined the tournament as, The nodes of digraph $D_{p}$ are $\{0,1, \ldots, p-1\}$ and $D_{p}$ contains the arc $(u, v)$ if and only if $u-v$ is a quadratic residue modulo $p$ where $p \equiv 3(\bmod 4)$ be a prime. This digraph is referred as the Paley tournament. Raymond Paley was a person raised Hadamard matrices by using this quadratic residues. So to honor him this tournament was named as Paley tournament. These results were extended by Bollobas for prime powers. Modular super edge trimagic labeling and modular super vertex magic total labeling has been investigated in this paper.
\end{abstract}

\section{AMS Subject Classification: $05 C 78$}

Key words: Super edge tri magic labeling, Paley Digraph and Modular Super vertex magic total labeling.

\section{INTRODUCTION}

This article has discussion about a strong regular digraph nodes collectively with set of arcs which is relating some subset of those nodes. One among different way to label the graph elements is labeling with integers. Labeling is defined as a mapping of a sequence of graph elements send to a sequence of real values (negative integers not allowed). Graph labeling has wide range of application in real life which is categorized as qualitative labeling and quantitative labeling. More than 2000 papers have been published in graph labeling and for more details one can refer [1]. Out of many types of labeling most fascinating labeling is magic labeling. It was originated from number theory especially [2] [3]. Stewart [4] have been studied about this labeling and named as super magic provided the labels are continuous integers, starting from 1 . Few researchers evidently termed "magic" as an alternative of "supermagic". Magic labeling is defined as a total labeling by Kotzig and Rosa [5], in which the tagging is from 1 to $|\mathrm{V}|+|\mathrm{E}|$. Super vertex-magic total labeling was introduced by MacDougall, et.al.[6](some implement the term "super vertex-magic" for the same notion). Magic labeling and super vertex (a,d) antimagic labeling for digraphs was introduced by K.Thirusangu et.al. [7].

C. Jayasekaran et.al.[8] introduced the labeling called edge trimagic total labeling. It is defined as a one to one and onto function $\mathrm{f}: \mathrm{V} \cup \mathrm{E} \rightarrow\{1,2, \ldots,|\mathrm{V}|+|\mathrm{E}|\} \ni, \forall$ edge $\mathrm{xy} \in$

Revised Version Manuscript Received on 10 September, 2019. ( Deemed to be University), Chennai, Tamil Nadu, India(Email: paramsumesh2011@gmail.com)

Rajeswari.R, Sathyabama Institute of Science and Technologyrajeswarivel@yahoo.in) called Paley digraph. Let us consider a graph $\mathrm{G}$ with set of from magic squares and was pioneered by Sedlacek in 1963

Parameswari.R, Sathyabama Institute of Science and Technology( Deemed to be University), Chennai, Tamil Nadu, India(Email:

$\mathrm{E}$, the sum of the arc and the node will be equal to any integers $k_{1}$ or $k_{2}$ or $k_{3}$ where $k_{i}$ are constants. If the nodes of $G$ are labeled with least positive integers then it is called as super edge trimagic total labeling. In 2014, the same labeling was extended for the digraphs by the same author. Using super vertex magic total labeling Modular super vertex magic labeling was introduced by D. Antony Xavier [9]. An injective function $\mathrm{f}: \mathrm{V} \cup \mathrm{E} \rightarrow\{1,2,3 \ldots|\mathrm{V}|+|\mathrm{E}|\}$ is called a modular vertex magic labeling if $\exists$ a constant $k \ni, f(x)+\sum f($ $\mathrm{xy})=\mathrm{k}(\bmod \mathrm{p}) \forall \mathrm{x} \in \mathrm{V}, 0 \leq \mathrm{k}<\mathrm{p}-1$. Paley digraph confess some members of family of magic labeling, also some deficiency of labeling and cordiality in various papers [10] [11] [12]. In the following section, modular edge trimagic and super vertex magic labeling has been discussed.

\section{RESULT AND DISCUSSION}

\section{MODULAR SUPER EDGE TRIMAGIC LABELING OF PALEY DIGRAPH}

\section{A. Theorem}

Suppose $\mathrm{P}(\mathrm{q})$ is a Paley digraph with Galois field elements as nodes $\mathrm{v}_{1}, \mathrm{v}_{2}, \ldots, \mathrm{v}_{\mathrm{q}}, \mathrm{q} \equiv 3(\bmod 4)$. If each nodes of $\mathrm{G}$ has $\mathrm{p}$ incoming and outgoing arcs with $|\mathrm{E}|=\mathrm{pq}$, where $\mathrm{p}=\left(\frac{q-1}{2}\right)$ then $\mathrm{P}(\mathrm{q})$ is super edge trimagic digraph.

\section{Proof}

Let us consider a Galois field element of order q, a prime number which is congruent to $3 \bmod 4$ as the nodes and construct a Paley digraph. We denote the node set $\mathrm{V}(\mathrm{P})$ as \{ $\left.\mathrm{v}_{1}, \mathrm{v}_{2}, \ldots, \mathrm{v}_{\mathrm{q}}\right\}$ and the arc set as $\mathrm{E}=\left\{\mathrm{E}_{1} \cup \mathrm{E}_{2} \cup \mathrm{E}_{3}\right\}$, where $E_{1}=\left\{e_{i} \quad 1 \leq i \leq p-1, \quad E_{2}=\left\{\begin{array}{ll}e_{j} & p \leq j \leq q-3\end{array}\right.\right.$, and $E_{a}= \begin{cases}e_{K} & q-2 \leq k \leq q\end{cases}$ trimagic digraph let us define the function as

$$
\mathrm{f}\left(\mathrm{v}_{\mathrm{i}}\right)=\mathrm{i} \quad 1 \leq \mathrm{i} \leq \mathrm{q}
$$

When $\mathrm{k}$ is odd

$$
\mathrm{f}\left(\mathrm{E}_{\mathrm{r}_{\mathrm{k}}}\left(\mathrm{e}_{\mathrm{i}}\right)\right)= \begin{cases}\mathrm{kq}+\mathrm{p}+2+1-\mathrm{i} & 1 \leq \mathrm{i} \leq \mathrm{p}-1 \\ \mathrm{kq}+3 \mathrm{p}+1-\mathrm{i} & \mathrm{p} \leq \mathrm{i} \leq \mathrm{q}-3 \\ (\mathrm{k}+1) \mathrm{q}+1-\mathrm{i} & \mathrm{q}-2 \leq \mathrm{i} \leq \mathrm{q}\end{cases}
$$

When $\mathrm{k}$ is even

$$
\mathrm{f}\left(\mathrm{E}_{\mathrm{r}_{\mathrm{k}}}\left(\mathrm{e}_{\mathrm{i}}\right)\right)=\{\mathrm{kq}+\mathrm{i} \quad 1 \leq \mathrm{i} \leq \mathrm{q}
$$

Summing up the labels of respective arc set to each node and the computation of each node gives either $\mathrm{k}_{1}$ or $\mathrm{k}_{2}$ or $\mathrm{k}_{3}$ respectively.

$$
\text { For } 1 \leq \mathrm{i} \leq \mathrm{p}-1
$$




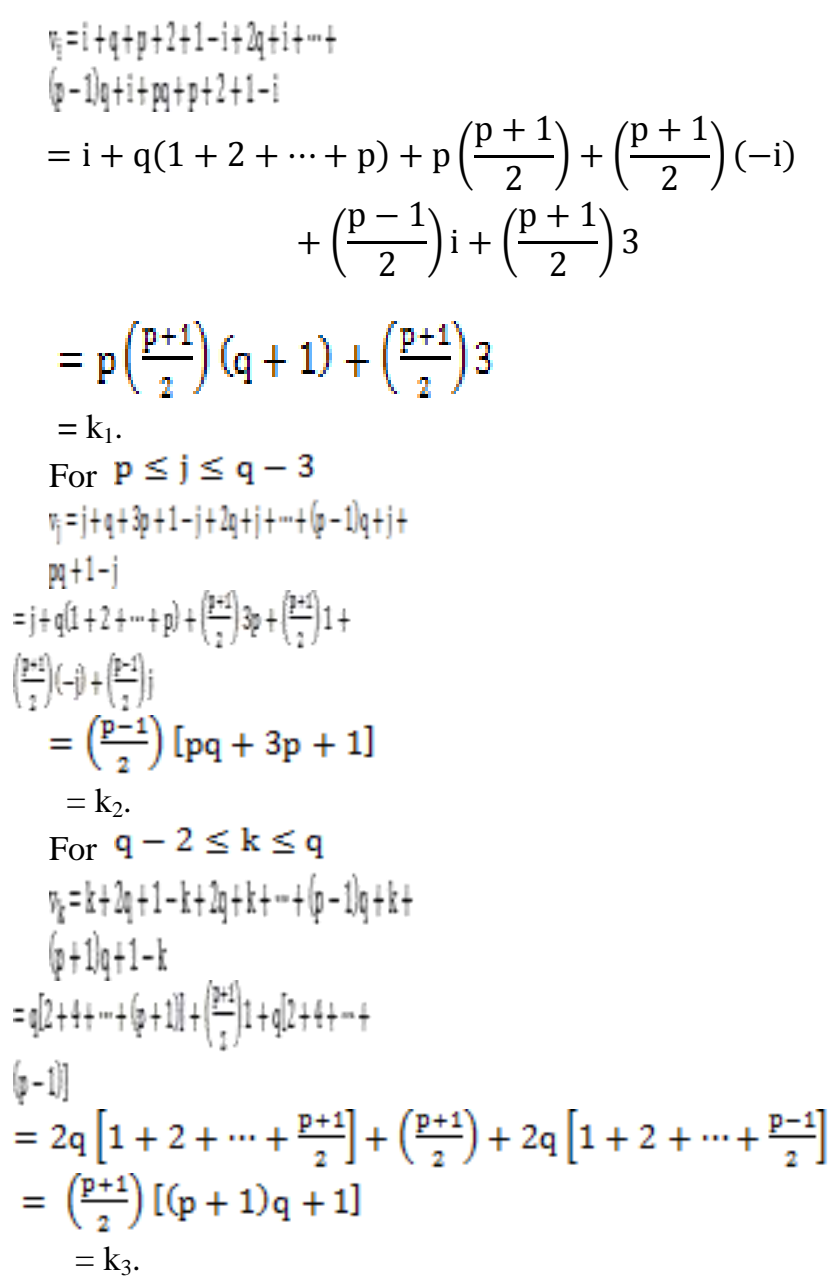

In this the node set is labeled as smaller values and this proved that $\mathrm{P}(\mathrm{q})$ is super edge trimagic graph.

\section{A. Illustration}

Paley digraph $\mathrm{P}(7)$ as super edge trimagic total graph .

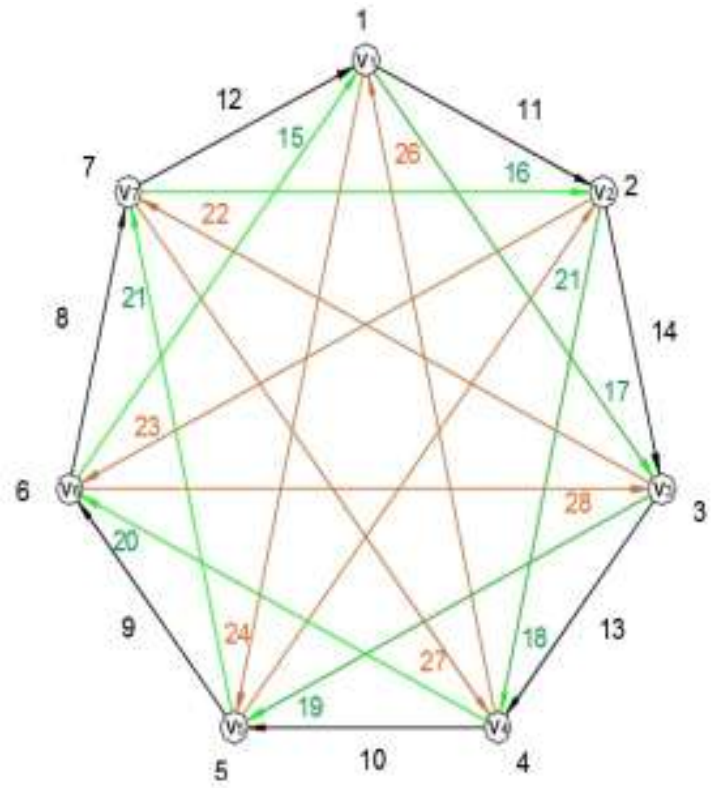

\section{B. Corollary}

If the directed graph $\mathrm{P}(\mathrm{q})$ where $\mathrm{q}$ is a prime number is super edge trimagic graph then by the definition of modular super vertex magic one can easily identify that this graph as well as a modular super edge trimagic digraph. But the contrary must not be true.

\section{MODULAR SUPER VERTEX MAGIC TOTAL LABELING}

\section{A. Proposition}

Let $\mathrm{G}$ be a digraph with finite field elements as vertices $\mathrm{v}_{1}$, $\mathrm{v}_{2}, \ldots, \mathrm{v}_{\mathrm{q}}, \mathrm{q}$ is prime and $\mathrm{q} \equiv 3(\bmod 4)$. If each vertex of $\mathrm{G}$ has $\mathrm{p}$ incoming and $\mathrm{p}$ outgoing arcs with $|\mathrm{E}|=\mathrm{pq}$, where $\mathrm{p}=\frac{q-1}{2}$ then $\mathrm{G}$ admits vertex magic total labeling.

\section{B. Algorithm}

Input: Galois field elements as nodes.

Step 1: Put together the nodes and arcs as directed graph $P(q)$

Step 2: The mapping $\mathrm{f}: \mathrm{V} \cup \mathrm{E} \rightarrow\{1,2, \ldots,|\mathrm{V}|+|\mathrm{E}|\}$ is defined as

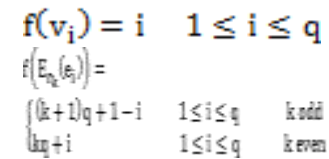

Output: Super vertex magic total labeling.

\section{Theorem}

Let $\mathrm{G}$ be a digraph with finite field elements as nodes $\mathrm{v}_{1}$, $\mathrm{v}_{2}, \ldots, \mathrm{v}_{\mathrm{q}}, \mathrm{q}$ a prime and congruent to $3(\bmod 4)$. If each node of $\mathrm{G}$ has $\mathrm{p}$ incoming and $\mathrm{p}$ outgoing arcs with $|\mathrm{E}|=\mathrm{pq}$, where $p=\frac{q-1}{2}$ then $G$ acknowledges super vertex magic total labeling.

\section{Proof}

Construct a strong regular directed graph by using the Galois field elements as its nodes and by Paley digraph definition. We symbolize the node set $\mathrm{V}(\mathrm{P})$ as $\left\{\mathrm{v}_{1}, \mathrm{v}_{2}, \ldots, \mathrm{v}_{\mathrm{q}}\right\}$ and the arc set as $E=\left\{E_{1} \cup E_{2} \cup \ldots \cup E_{p}\right\}, p=\frac{q-1}{2}$. To establish every directed Paley graph is super vertex magic total graph, exemplify that for every vertex $v_{i}$, the totting up of the labels of $v_{i}$ with its leaving arcs raise a constant. Using the function from the above algorithm, for each vertex the totting up of the labels is given by

$$
\begin{aligned}
& =q\left(\frac{p+1}{2}\right)\left[\frac{p+3}{2}+\frac{p-1}{2}+\frac{1}{q}\right] \\
& =\frac{(q+p q)(q+p q+1)}{2 q}
\end{aligned}
$$

$=\mathrm{k}$ a constant.

Here the nodes are labeled with smaller numbers. From this one can conclude that the digraph is super vertex magic total graph.

\section{D.Illustration}

Paley digraph $\mathrm{P}(7)$ with super vertex magic total labeling. 


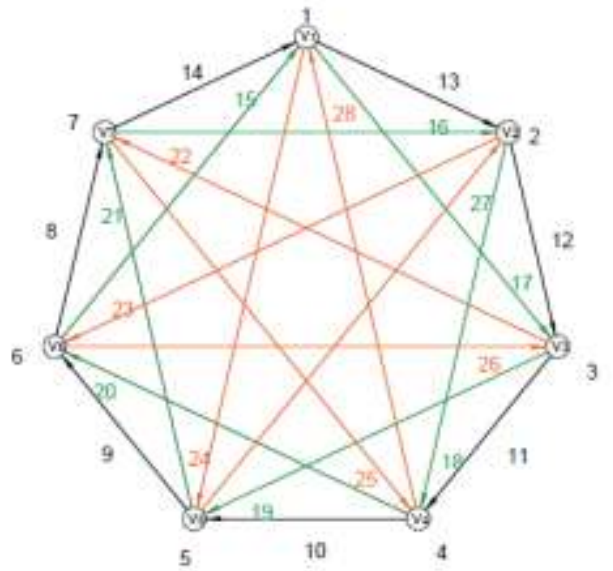

\section{E. Corollary}

If the directed graph $\mathrm{P}(\mathrm{q})$ where $\mathrm{q}$ is a prime number is super vertex magic total graph then it is also a modular super vertex magic total digraph. But the converse need not be true.

\section{BOUND ON MAGIC CONSTANT}

\section{A. Theorem}

Let $\mathrm{G}$ be a quadratic residue digraph with $\mathrm{q}$ vertices and $\mathrm{pq}$ edges. Suppose the sum of the edge labeling of the Hamiltonian circuit is $\alpha \mathrm{q}$ where ' $\alpha$ ' is $\mathrm{mq}+\mathrm{p}+1, \mathrm{~m}=1,2$, $\ldots, \frac{\mathrm{q}-1}{2}$, a constant. If $\mathrm{G}$ is admits super vertex magic total labeling with a magic constant $\mathrm{k}$, then $\frac{\mathrm{q}(\mathrm{q}+\mathrm{p}+1)+1}{2} \leq \mathrm{k} \leq$ $q\left(\frac{q+2 p q+1}{2}\right)$.

\section{Proof}

Every strong regular digraph has Hamiltonian circuit. Since $\mathrm{P}(\mathrm{q})$ is also a strong regular directed graph it has a Hamiltonian circuit and its measurement lengthwise is q. The computation of the arc labeling of the tour is $\alpha \mathrm{q}$ and $\alpha=$ $\mathrm{mq}+\mathrm{p}+1$ where $\mathrm{m}=1,2, \ldots, \frac{q-1}{2}$.The node labeling is excluded in the route. The accumulation of labeled arc of the circuit with minimal residue lessen the value and the accumulation of labeled arc with maximal residue maximize the value as $\frac{\mathrm{q}(\mathrm{q}+\mathrm{p}+1)+1}{2} \leq \mathrm{k} \leq \mathrm{q}\left(\frac{\mathrm{q}+2 \mathrm{pq}+1}{2}\right)$.

\section{CHARACTERIZATION OF EDGE GRACEFUL LABELING ON PALEY DIGRAPH}

Based on the structural properties of Paley digraph and the definition of edge graceful labeling and antimagic labeling on digraphs, a characterization of labeling is derived on Paley digraph.

\section{A.Theorem}

Let $\mathrm{G}$ be a quadratic residue digraph with finite field elements as vertices $v_{1}, v_{2}, \ldots, v_{q}, q$ is prime and $q \equiv 3(\bmod$ 4). If each vertex of $G$ has $p$ incoming and $p$ outgoing arcs with $|E|=p q$, where $p=\frac{q-1}{2}$ then $G$ is edge graceful if and only if it is antimagic.

\section{Proof}

Consider the Paley digraph $\mathrm{P}(\mathrm{q})$ with $\mathrm{q}$ vertices and $\mathrm{pq}$ edges where $\mathrm{p}=\frac{\mathrm{q}-1}{2}$. Under edge graceful labeling, we define a bijective mapping $\mathrm{f}: \mathrm{E} \rightarrow\{1,2, \ldots, \mathrm{pq}\}$ such that the induced mapping $\mathrm{f}^{*}: \mathrm{V} \rightarrow\{0,1, \ldots, \mathrm{q}-1\}$ given by $\mathrm{f}^{*}\left(\mathrm{v}_{\mathrm{j}}\right)=$ $\sum_{\mathrm{i}=1}^{\mathrm{p}} \mathrm{f}\left(\mathrm{e}_{\mathrm{ij}}\right)(\bmod \mathrm{q}), 1 \leq \mathrm{j} \leq \mathrm{q}$ is distinct. In the case of antimagic labeling we define a bijective mapping $\mathrm{f}: \mathrm{E} \rightarrow\{1$, $2, \ldots, \mathrm{pq}\}$ such that the induced mapping $\mathrm{f}^{*}: \mathrm{V} \rightarrow\{1,2, \ldots, \mathrm{N}\}$ given by $\mathrm{f}^{*}\left(\mathrm{v}_{\mathrm{j}}\right)=\sum_{\mathrm{i}=1}^{\mathrm{p}} \mathrm{f}\left(\mathrm{e}_{\mathrm{ij}}\right), 1 \leq \mathrm{j} \leq \mathrm{q}$ is distinct. If $\mathrm{P}(\mathrm{q})$ admits edge graceful labeling then $f^{*}\left(v_{j}\right)=\sum_{i=1}^{p} f\left(e_{i j}\right)(\bmod$ $\mathrm{q}), 1 \leq \mathrm{j} \leq \mathrm{q}$ gives $\mathrm{q}$ distinct values. Since $\mathrm{f}^{*}\left(\mathrm{v}_{\mathrm{j}}\right)$ is independent of vertex labels, $\mathrm{f}^{*}\left(\mathrm{v}_{\mathrm{j}}\right)=\sum_{\mathrm{i}=1}^{\mathrm{p}} \mathrm{f}\left(\mathrm{e}_{\mathrm{ij}}\right), 1 \leq \mathrm{j} \leq \mathrm{q}$ also gives distinct $q$ values. Hence $\mathrm{P}(\mathrm{q})$ admits antimagic labeling.

\section{REFERENCES}

1. Gallian, J.A, "A dynamic survey of graph labeling, "The Electronic Journal of Combinatory 18,(2015), \#DS6

2. J. Sedlacek, Problem 27, in Theory of Graphs and its Applications, Proc. Symposium Smolenice, June, (1963) 163-167.

3. J. Sedlacek, On magic graphs, Math. Slov., 26 (1976) 329-335.

4. B. M. Stewart, Supermagic complete graphs, Canadian J. Math., 19 (1967) 427- 438.

5. A. Kotzig and A. Rosa, Magic valuations of complete graphs, Centre de Recherches Mathematiques, Universite de Montreal, (1972) CRM-175.

6. J. A. MacDougall, M. Miller, and K. Sugeng, Super vertex-magic total labelings of graphs, Proceedings Australasian Workshop Combin. Algorithm 2004, Balina, NSW (2004) 222-229.

7. Thirusangu K, Atulya K. Nagar, Rajeswari R,. Labeling in cayley digraphs, European Journal of Combinatorics. Science Direct, Elsevier. 2011; 32(1) 133-139.

8. C. Jayasekaran, M. Regees and C. Davidraj, "Edge Trimagic Labeling of Some Graphs" Accepted for publication in the, International Journal of Combinatorial Graph Theory and Applications.

9. D. Antony Xavier, " Modular Super vertex magic Total labeling", Journal of Computing Algorithm Integrated Intelligent Research, 03,(2014), 606-608.

10. Parameswari.R, Rajeswari.R, "Total Bimagic and Total Magic Cordial labeling of Paley Digraphs" PRIME 2013, No:978-1-4673-5844- 6 978-14673-5845-3/13/\$31.00@ 2013 IEEE.

11. Parameswari.R, Rajeswari.R,"Labeling of Quadratic residue digraphs over finite field" Smart Innovation, Systems and Technologies, Springer, 50(2016) 387-396.

12. Parameswari. R, Rajeswari.R, " On Cordial and Antimagicness of Quadratic Residue Digraph" Journal of Computational and Theoretical NanoScience, American Scientific Publishers, 14 (2017), 4553-4555. 